\title{
Monocyte-Derived Dendritic Cells Can Revert In Vitro Antigen-Specific Cellular Anergy in Active Human Paracoccidioidomycosis
}

\author{
Paula Keiko Sato 1,2,3,*(D), Telma Miyuki Oshiro 1,4 , Érika Cano Passos ${ }^{2,3}$, Tatiana Giselle Rodrigues Miranda 1,2 \\ Constância Lima Diogo ${ }^{2,3}$, Claudia de Abreu Fonseca ${ }^{2,3}$, Aya Sadahiro ${ }^{1,5}$, Sandro Rogério de Almeida 6 and \\ Maria Aparecida Shikanai-Yasuda 1,2,3,*iD
}

\section{check for}

updates

Citation: Sato, P.K.; Oshiro, T.M.; Passos, É.C.; Miranda, T.G.R.; Diogo, C.L.; Fonseca, C.d.A.; Sadahiro, A.; de Almeida, S.R.; Shikanai-Yasuda, M.A. Monocyte-Derived Dendritic Cells Can Revert In Vitro Antigen-Specific Cellular Anergy in Active Human Paracoccidioidomycosis. J. Fungi 2021, 7, 201. https://doi.org/ 10.3390/jof7030201

Received: 12 November 2020 Accepted: 8 January 2021 Published: 10 March 2021

Publisher's Note: MDPI stays neutral with regard to jurisdictional clai$\mathrm{ms}$ in published maps and institutional affiliations.

Copyright: (C) 2021 by the authors. Licensee MDPI, Basel, Switzerland. This article is an open access article distributed under the terms and conditions of the Creative Commons Attribution (CC BY) license (https:// creativecommons.org/licenses/by/ $4.0 /)$.
1 Departament of Infectious Diseases, Faculdade de Medicina FMUSP, Universidade de Sao Paulo, Sao Paulo 05403-000, Brazil; tmoshiro@yahoo.com (T.M.O.); tati.biomedica@hotmail.com (T.G.R.M.); ayasadahiro@gmail.com (A.S.)

2 Laboratory of Medical Investigation in Immunology (LIM-48), Hospital das Clinicas HCFMUSP, Faculdade de Medicina, Universidade de Sao Paulo, Sao Paulo 05403-000, Brazil; erikafootstep@yahoo.com.br (É.C.P.); constanciadl@yahoo.com.br (C.L.D.); c.lau.2007@hotmail.com (C.d.A.F.)

3 Institute of Tropical Medicine, Faculdade de Medicina FMUSP, Universidade de Sao Paulo, Sao Paulo 05403-000, Brazil

4 Laboratory of Medical Investigation in Dermatology and Immunodeficiencies (LIM-56), Hospital das Clinicas HCFMUSP, Faculdade de Medicina, Universidade de Sao Paulo, Sao Paulo 05403-000, Brazil

5 Departament of Parasitology, Instituto de Ciências Biológicas, Universidade Federal do Amazonas, Manaus 69080-900, Brazil

6 Department of Clinical and Toxicological Analysis, Faculty of Pharmaceutical Sciences, Universidade de Sao Paulo, Sao Paulo 05508-000, Brazil; sandroal@usp.br

* Correspondence: paula.s@hc.fm.usp.br (P.K.S.); masyasuda@yahoo.com.br (M.A.S.-Y.)

\begin{abstract}
We investigated the in vitro effects of two Paracoccidioides brasiliensis antigens on monocytederived dendritic cells (moDCs) from patients with paracoccidioidomycosis (PCM). MoDCs from patients with active or treated PCM and non-PCM subjects were generated, stimulated with TNF- $\alpha$, and P. brasiliensis antigens, $43 \mathrm{kDa}$ glycoprotein (gp43) and cell-free antigen (CFA), and analyzed by flow cytometry and enzyme-linked immunosorbent assays (ELISA). Our data revealed that patients with PCM had a high frequency of HLA-DR ${ }^{+}$cells, but the treated group had more $\mathrm{CD} 86^{+}$cells with increased IL-12p40. Patients with active PCM had more CD80 $0^{+}$moDCs, and as a novel finding, large amounts of chemokine (C-C motif) ligand 18 (CCL18) in the supernatants from their in vitro moDC cultures. Both gp43- and CFA-stimulated moDCs from the patients with PCM successfully reverted the in vitro antigen-specific anergy, inducing a proliferative response. However, CFA-stimulated moDCs led to higher lymphoproliferation, with increased IFN- $\gamma$ and TNF- $\alpha$ in the cells from the patients with active PCM compared with gp43. These original results combined with constant IL-10 and increased IL-12p40 levels suggest that a more complex antigen, such as CFA, may be a better inducer of the protective Th1 immune response than purified gp43 is, and a suitable target for future studies on anti-P. brasiliensis dendritic cell (DC)-based vaccines.
\end{abstract}

Keywords: Paracoccidioides brasiliensis; paracoccidioidomycosis; dendritic cells; cytokines; coculture; gp43; cell-free antigen

\section{Introduction}

The leading cause of nosocomial mortality among systemic mycosis patients in Brazil is paracoccidioidomycosis (PCM) [1]. This chronic systemic mycosis is endemic in Latin America and caused by dimorphic pathogenic fungal agents from the Paracoccidioides brasiliensis (P. brasiliensis) complex and Paracoccidioides lutzii [2-4]. In the lungs, conidia may undergo conversion to infective yeast form leading to a broad spectrum of clinical 
manifestations. More commonly, the fungus remains in a latent stage resulting in asymptomatic infection $[5,6]$. Other factors such as virulence of the fungal agent and immune responses may determine the severity of the disease and its clinical forms.

The T-helper (Th) 1 immune response with effective axis IFN- $\gamma /$ IL-12 plays an important protective role in the resistance to $P$. brasiliensis $[7,8]$ and in the asymptomatic PCM infection $[9,10]$. The chronic form presents a Th17/Th22 profile, with high production of IL-17 and IL-22, also secreting Th1 cytokines such as IFN- $\gamma$, TNF- $\alpha$, IL-2, and variable levels of IL-10 and IL-4, and increased levels of specific IgG1 antibodies, contributing to milder clinical manifestations. The acute form of PCM, in turn, shows a mixed Th2/Th9 response associated with susceptibility: increased levels of IL-4, IL-5, IL-9, IL-10, and TGF- $\beta$; low production of IFN- $\gamma$ and TNF- $\alpha$; and high levels of specific IgG4 and IgE antibodies $[9,10]$. Moreover, patients with disseminated PCM present an imbalance in cytokine profile and transitory anergy of the in vitro $P$. brasiliensis antigen-specific cellular immune response during active disease, but recover after successful antifungal treatment [11,12].

Dendritic cells (DCs) are key players in the modulation of those adaptive immune responses, described as professional antigen-presenting cells (APCs) found in the majority of tissues capturing and processing infectious agents. After migrating to peripheral lymph nodes, DCs maturate and express high amounts of costimulatory molecules and the major histocompatibility complex (MHC)-peptide complex, establishing an interaction with Tcells. This immune synapse along with the sort of captured antigen may define the resulting effector T cell response [13,14].

In the murine model of PCM, DCs from resistant mice were shown to be more efficient in inducing lymphocyte proliferation and Th1 cytokines than cells from susceptible animals, which had a preferential response of B cells and macrophages $[15,16]$. Regardless, DCs from both susceptible and resistant mice showed decreased expression of MHC-II and adhesion molecules, and lower levels of IL-12 when primed with P. brasiliensis or gp43 in vitro $[17,18]$.

On cutaneous lesions from patients with PCM, Langerhans cells were shown to be in reduced numbers, and the presence of factor XIIIa+ dermal dendrocytes, dermal DCs and plasmacytoid DCs was also reported [19-22]. Some reports demonstrated relevant effects of $P$. brasiliensis on monocyte-derived dendritic cells (moDCs) from healthy donors, especially on innate immunity mechanisms [23-26], but few investigated these cells from patients with PCM $[27,28]$.

Previously, we showed higher expression of Human Leukocyte Antigen-DR isotype (HLA-DR), CD86, and Dendritic Cell-Specific Intercellular adhesion molecule-3-Grabbing Non-integrin (DC-SIGN), and upregulation of IL-12p40 in moDCs from patients with treated PCM compared with in control subjects and patients with the active disease [28]. In the present study, we investigated the effects of two different $P$. brasiliensis antigens on moDCs from patients with active and treated PCM, and we show new perspectives on the modulation of immune responses towards protection and better outcomes.

\section{Materials and Methods}

\subsection{Paracoccidioidomycosis (PCM) Patients and Control Subjects}

In total, 53 patients with PCM diagnosis were included in this study: 24 with active PCM and 29 with treated PCM. All patients were selected at the Systemic Mycosis Outpatient Clinic of the Infectious Diseases Division of Hospital das Clinicas HCFMUSP, Faculdade de Medicina, University of Sao Paulo. Identification of Paracoccidioides spp. by mycological, and/or histopathological examination, and/or the presence of anti- $P$. brasiliensis serum antibodies (titers of $\geq 32$ in counterimmunoelectrophoresis test) at the moment of enrollment confirmed the diagnosis of active PCM. Confirmed diagnosis of PCM in the past, the absence of clinical symptoms, and specific antibody titers of $\leq 4$ for a period of at least 6 months determined treated PCM. The control group consisted of 30 non-PCM subjects: individuals considered healthy without a previous history of the disease or detectable anti-P. brasiliensis serum antibodies (by immunodiffusion test), and 
not sensitized in lymphoproliferation assays against the $43 \mathrm{kDa}$ glycoprotein of P. brasiliensis. Subjects with comorbidities such as neoplasia and other acute or chronic systemic infectious diseases were excluded. More data about the PCM patients and control subjects can be found in Table S1, Supplementary Material.

\subsection{P. brasiliensis Antigens}

Antigens gp43 [29] and cell-free antigen (CFA) [30] were obtained as previously described. Briefly, gp43 was purified at the Laboratory of Mycology from the Institute of Biomedical Sciences (University of Sao Paulo, Sao Paulo, SP, BR) and at the Laboratory of Medical Investigation in Immunology (HCFMUSP) from the exoantigen of $P$. brasiliensis yeast B-339 strain through an adsorbent column with murine monoclonal antibody antigp43 coupled to an Affi-Gel 10 column (Bio-Rad, Hercules, CA, USA). Gp43 was eluted with acid buffer ( $\mathrm{pH}$ 2.8) and neutralized with $1 \mathrm{M}$ Tris ( $\mathrm{pH}$ 9.0). The material was concentrated in a 10K Amicon apparatus (Merck Millipore, Darmstadt, Germany). CFA was obtained by mixing a suspension of $P$. brasiliensis yeast B-339 strain in RPMI 1640 medium (Gibco, Grand Island, NY, USA) in a vortex mixer and immediately centrifuging at $10,000 \times g$. The resulting supernatant fluid contained the antigen. Both gp43 and CFA had their protein contents determined by the Bradford method [31], confirmed by sodium dodecyl sulfate-polyacrylamide gel electrophoresis (SDS-PAGE) [32], and stored at $-80^{\circ} \mathrm{C}$ until use.

\subsection{Monocyte-Derived Dendritic Cells (MoDCs) Generation and Stimulation}

Monocyte-derived DCs were generated from peripheral blood mononuclear cells (PBMCs) by a modification of previously described methods [33,34]. PBMCs from all subjects were isolated by Ficoll-Hypaque density gradient (GE Healthcare Life Sciences, Uppsala, Sweden) and washed in RPMI 1640 medium (Gibco, Grand Island, NY, USA). Cells $\left(1 \times 10^{7} / \mathrm{mL}\right)$ were added to 6-well flat bottom plates (Corning, Steuben, NY, USA) and allowed to adhere for $2 \mathrm{~h}$ in a $37^{\circ} \mathrm{C}$ incubator with $5 \% \mathrm{CO}_{2}$. Non-adherent cells were removed by several washes with RPMI 1640 medium (Gibco, Grand Island, NY, USA) and frozen at $-80{ }^{\circ} \mathrm{C}$ for future use. Adherent cells were cultured for 6 days in RPMI 1640 medium (Gibco, Grand Island, NY, USA) supplemented with gentamicin (40 mg/L), fetal calf serum (10\%; Gibco, Grand Island, NY, USA), L-glutamine ( 2 mol/L; Gibco, Grand Island, NY, USA), recombinant IL-4 (50 ng/mL; PeProtech, Rocky Hill, NJ, USA), and granulocyte-macrophage colony-stimulating factor (GM-CSF, $50 \mathrm{ng} / \mathrm{mL}$; PeProtech, Rocky Hill, NJ, USA). On days 3 and 6, fresh RPMI 1640 medium containing IL-4 and GM-CSF was added to the cultures. On Day 6, cells were harvested and split into 24-well flat bottom plates $\left(1 \times 10^{6}\right.$ cells $/ \mathrm{mL}$; Corning, Steuben, NY, USA). MoDCs were then stimulated with gp43 $(5 \mu \mathrm{g} / \mathrm{mL})$ or CFA $(15 \mu \mathrm{g} / \mathrm{mL})$, with or without recombinant TNF- $\alpha(50 \mathrm{ng} / \mathrm{mL}$; PeProtech, Rocky Hill, NJ, USA), or left untreated (Medium) for $48 \mathrm{~h}$ in a $37^{\circ} \mathrm{C}$ incubator with $5 \% \mathrm{CO}_{2}$.

\subsection{Flow Cytometric Analyses}

The effects of gp43 and CFA on moDC surface molecules expression were investigated by flow cytometry after $48 \mathrm{~h}$ of incubation. Specific PE- or FITC-conjugated monoclonal antibodies anti-CD11c, -CD14, -CD1a, -HLA-DR, -CD80,-CD86 (Caltag Medsystems, Buckingham, UK), DC-SIGN (R\&D Systems, Minneapolis, MN, USA) and respective mouse isotype controls were used. Cells $\left(1 \times 10^{6} / \mathrm{mL}\right)$ were stained for $30 \mathrm{~min}$ with manufacturer's recommended concentrations of mAbs on PBS with fetal calf serum $(10 \%$; Gibco, Grand Island, NY, USA) to block any non-specific binding, on ice and in the dark, and then washed 3 times with PBS before acquisition and analysis on a FACSCalibur flow cytometer and CellQuest software (BD Biosciences, San Jose, CA, USA). Results are expressed as percentages of positively stained cells with specific antibodies. Data regarding the gating strategy can be found in Figure S1, Supplementary Material. 


\subsection{Antigen Presentation Assays}

PBMCs from PCM and non-PCM control subjects were isolated by Ficoll-Hypaque (GE Healthcare Life Sciences Uppsala, Sweden) density gradient and washed in RPMI 1640 medium (Gibco, Grand Island, NY, USA). Cells $\left(21 \times 10^{6} / \mathrm{mL}\right)$ were added to a 96 well flat bottom microplate in triplicate wells (Corning, Steuben, NY, USA) and stimulated with phytohemagglutinin (PHA; $5 \mu \mathrm{g} / \mathrm{mL}$; Sigma-Aldrich, St. Louis, MO, USA), gp43 $(1 \mu \mathrm{g} / \mathrm{mL}$; determined in a previous study [35]), CFA (2 and $5 \mu \mathrm{g} / \mathrm{mL})$ or left unstimulated (Medium) at a final volume of $200 \mu \mathrm{L} /$ well in a $37^{\circ} \mathrm{C}$ incubator with $5 \% \mathrm{CO}_{2}$. Lymphoproliferation was verified on the microplates after $120 \mathrm{~h}$ by measuring $\left[{ }^{3} \mathrm{H}\right]$-thymidine uptake $\left(9.25 \times 10^{4} \mathrm{~Bq} / \mathrm{mL}\right.$; GE Healthcare Life Sciences, Uppsala, Sweden) during the last $8 \mathrm{~h}$ of the assay on a beta plate scintillation counter (Perkin-Elmer, Waltham, MA, USA).

MoDCs were stimulated with $P$. brasiliensis antigens or left untreated as described in Section 2.3. After $48 \mathrm{~h}$, moDCs were irradiated with $15 \mathrm{G} \gamma$ from a ${ }^{60} \mathrm{Co}$ source and plated at $1 \times 10^{5}$ cells $/ \mathrm{mL}$ in triplicate wells on 96-well flat-bottom microplates (Corning, Steuben, NY, USA). Autologous non-adherent cells were added at $5 \times 10^{5}$ cells $/ \mathrm{mL}$ (final volume of $200 \mu \mathrm{L} /$ well), and microplates were incubated at $37^{\circ} \mathrm{C}$ with $5 \% \mathrm{CO}_{2}$. Triplicate wells with unstimulated moDCs in medium, non-adherent cells in medium and non-adherent cells with PHA $5 \mu \mathrm{g} / \mathrm{mL}$ (Sigma-Aldrich, St. Louis, MO, USA) were used as controls for the assay. The lymphoproliferation was verified after $120 \mathrm{~h}$ by measuring $\left[{ }^{3} \mathrm{H}\right]$-thymidine uptake $\left(9.25 \times 10^{4} \mathrm{~Bq} / \mathrm{mL}\right.$; GE Healthcare Life Sciences, Uppsala, Sweden) during the last $8 \mathrm{~h}$ of the assay on a beta plate scintillation counter (Perkin-Elmer, Waltham, MA, USA).

Results are expressed as the difference between mean counts per minute of triplicates $(\delta \mathrm{cpm})$ of stimulated and unstimulated cells (Medium).

\subsection{Cytokine Analyses}

In primary cultures, moDCs were stimulated with $P$. brasiliensis antigens, with or without TNF- $\alpha$, or left untreated. Culture supernatants were harvested after $48 \mathrm{~h}$ of incubation, and cytokines production were assayed by enzyme-linked immunosorbent assay (ELISA) for IL-12p40, IL-1 $\beta$, IL-10 (BD Biosciences, San Jose, CA, USA), and chemokine (C-C motif) ligand 18 (CCL18) (R\&D Systems, Minneapolis, MN, USA), according to manufacturer's instructions. MoDCs and autologous non-adherent cells were cocultured and supernatants were harvested after $144 \mathrm{~h}$ of incubation for cytokines levels detection by ELISA for IFN- $\gamma$, TNF- $\alpha$, IL-4, and IL-10 (BD Biosciences, San Jose, CA, USA) according to the manufacturer's instructions. IFN- $\gamma$ levels were also determined on supernatants from the PBMC cultures after $144 \mathrm{~h}$ of incubation by ELISA assay (BD Biosciences, San Jose, CA, USA) according to the manufacturer's instructions.

Results are expressed as picograms per milliliter (pg/mL), except for CCL18, which is expressed as nanograms per milliliter $(\mathrm{ng} / \mathrm{mL})$.

\subsection{Statistical Analyses}

Statistical significance of differences between moDCs from the evaluated groups regarding the expression of surface molecules, the induction of lymphoproliferation, or cytokine release was assessed by one-way ANOVA. When values $p<0.05$ in ANOVA, Bonferroni's multiple-comparison test was used (all $p$ values from ANOVA are detailed in Table S2a-d, Supplementary Material). Results are represented as means with standard error of mean (SEM), and values of $p<0.05$ were considered statistically significant. All results were analyzed using Graph-Pad Prism 5.01 software (GraphPad Software, San Diego, CA, USA).

\section{Results}

\subsection{P. brasiliensis Antigens Modulate Surface Molecule Expression on MoDCs from PCM Patients}

MoDCs from patients with active and treated PCM, and from non-PCM control subjects were differentiated from monocytes on in vitro cultures. Cells were stimulated with TNF- $\alpha$ or left untreated, and flow cytometric analysis was conducted to investigate the 
expression of CD14 (monocyte marker), CD11c and CD1a (dendritic cell markers), HLA-DR (MHC class II human antigenic presentation molecule), CD80 and CD86 (costimulatory molecules), and DC-SIGN (C-type lectin receptor). The resulting cells from all groups had morphological characteristics of DCs on optical microscopy observation, and were $>80 \% \mathrm{CD} 11 \mathrm{c}^{+} \mathrm{CD} \mathrm{a}^{+}$and $<5 \% \mathrm{CD} 4^{+}$on flow cytometric analysis, indicating successful differentiation of DCs from monocytes. With the addition of TNF- $\alpha$, these cells were activated, resulting in the increased expression of HLA-DR and CD86 [36].

We then investigated the effects of gp43 and CFA on the expression of surface molecules on moDCs (Figure 1). We evaluated three different concentrations of each antigen on moDC cultures from patients with treated PCM; gp43 with TNF- $\alpha$ down-regulated CD86 and DC-SIGN when compared with TNF- $\alpha$ alone, and CFA with or without TNF- $\alpha$ decreased DC-SIGN when compared with moDCs and Medium alone or TNF- $\alpha$ alone. Given that gp 43 at $5 \mu \mathrm{g} / \mathrm{mL}$ and CFA at $15 \mu \mathrm{g} / \mathrm{mL}$ had more noticeable effects on modifying the percentages of those molecules on gated moDCs (without statistically significant differences), we chose them for further experiments with all groups.

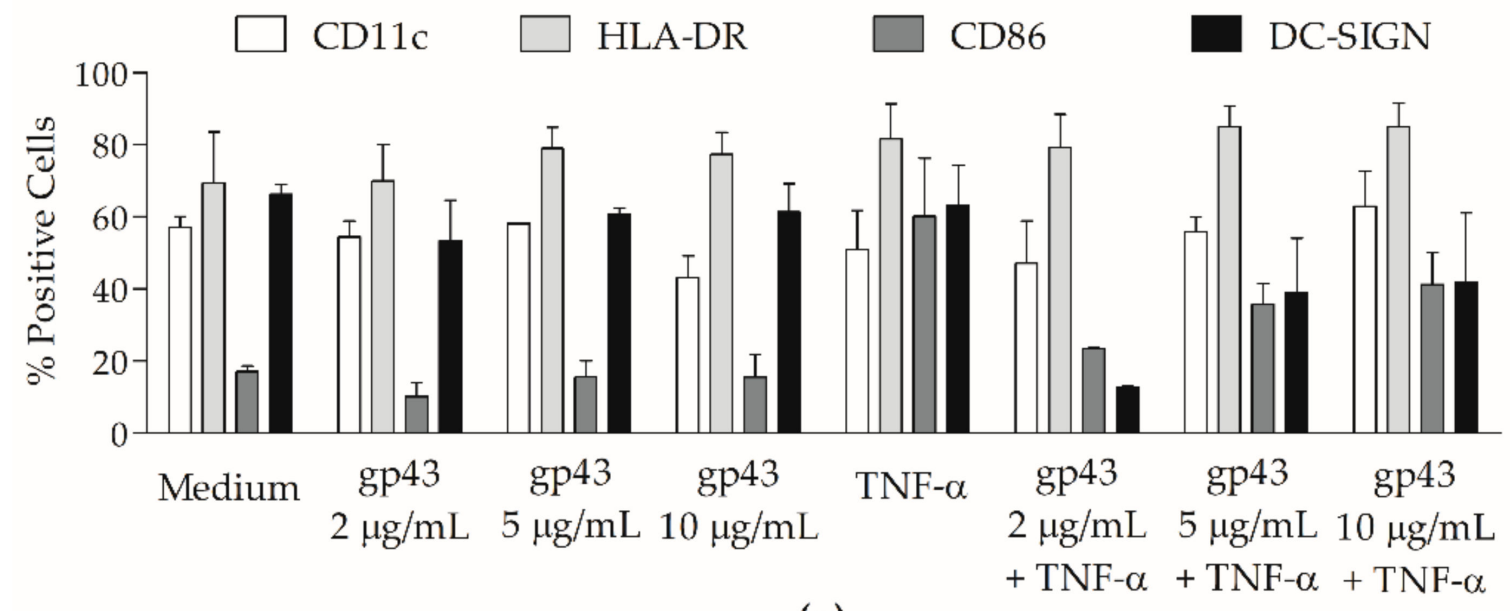

(a)

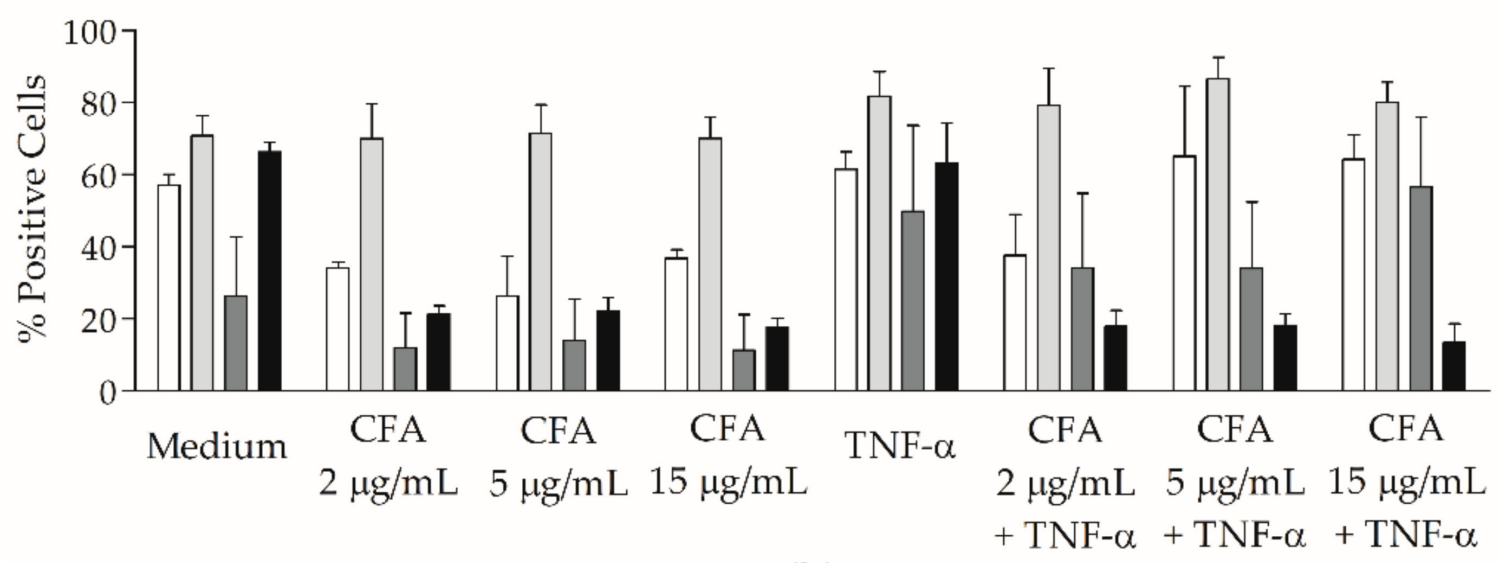

(b)

Figure 1. Influence of different concentrations of gp43 and cell-free antigen (CFA) of $P$. brasiliensis on expression of surface molecules by monocyte-derived dendritic cells (moDCs): Percentages of CD11c ${ }^{+}$(white bars), HLA-DR ${ }^{+}$(light grey bars), $\mathrm{CD}^{+} 6^{+}$(dark grey bars) and DC-SIGN ${ }^{+}$(black bars) cells were analyzed by flow cytometry on moDCs from patients with treated PCM $(n=3)$, after $48 \mathrm{~h}$ of stimulation with (a) gp43 2, 5 or $10 \mu \mathrm{g} / \mathrm{mL}$; and (b) CFA 2, 5 or $15 \mu \mathrm{g} / \mathrm{mL}$, with or without TNF- $\alpha$, or without any treatment (Medium). Results expressed as means with standard errors of the mean (SEM) of percentages of positive cells. There were no statistically significant differences. 


\subsection{Patients with Active PCM Have More $C D 80^{+}$Cells and $C D 86^{+}$Cells Are Augmented after Antifungal Treatment}

After incubation for $48 \mathrm{~h}$, the frequencies of HLA-DR ${ }^{+}$moDCs from the active PCM group were significantly lower than those of the treated group when cells were stimulated with gp43 or left unstimulated ( $p<0.05$ on both comparisons; Figure 2a). This antigen and TNF- $\alpha$ also increased the mean fluorescence intensity (MFI) of HLA-DR on moDCs from treated patients when compared with cells from the active PCM group $(p<0.05$; Figure S2a). Interestingly, both groups of PCM patients had higher percentages of $\mathrm{CD}^{+} 6^{+}$unstimulated cells than non-PCM subjects did (both $p<0.05$ ); however, only moDCs from treated patients showed this increase when stimulated with gp 43 or CFA $(p<0.01$ and $p<0.05$, respectively; Figure $2 b$ ). No differences in the number of $C D 86^{+}$cells were observed between the groups in the presence of TNF- $\alpha$, and frequencies of DC-SIGN ${ }^{+}$cells were similar in all groups with or without stimuli (Figure 2c). Gp43 significantly decreased the percentages of CD80 $0^{+}$ cells from the treated PCM group. Conversely, moDCs from the active disease group had higher frequencies of positive cells than those of treated patients in the presence of gp43 with or without TNF- $\alpha$ (Figure 2d).

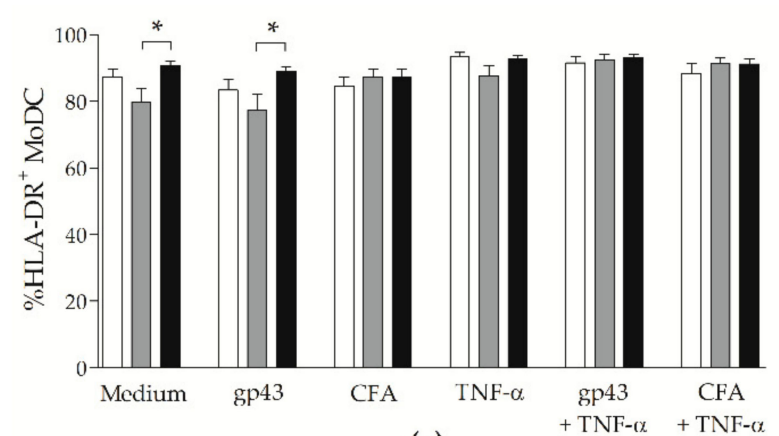

(a)

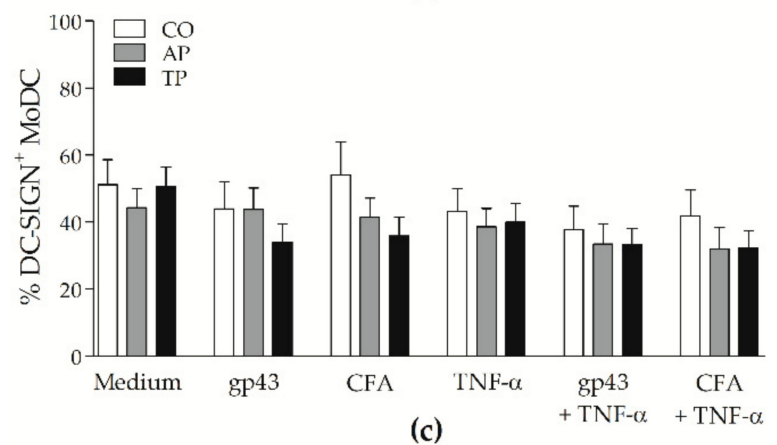

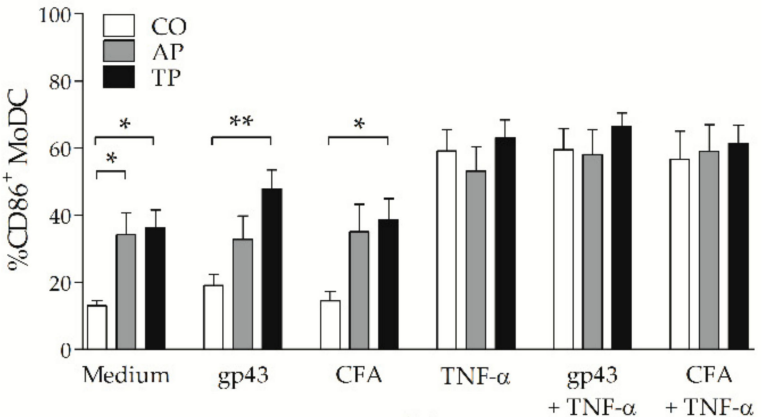

(b)

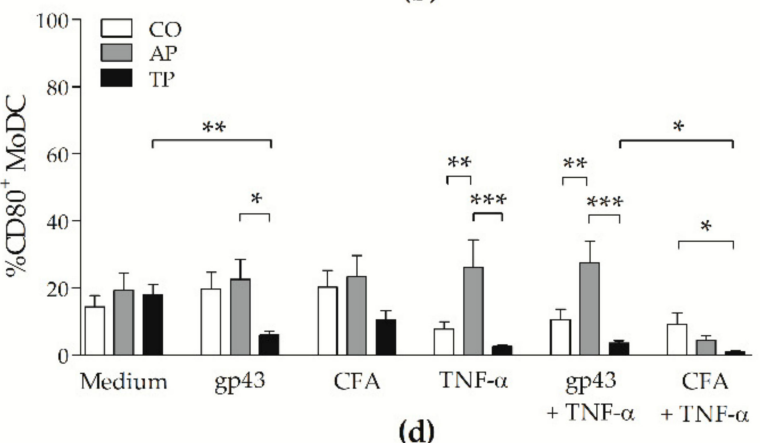

(d)

Figure 2. Influence of gp43 and CFA of P. brasiliensis on expression of surface molecules by moDCs: Percentages of (a) HLA$\mathrm{DR}^{+}$, (b) $\mathrm{CD}^{+} 6^{+}$, (c) DC-SIGN ${ }^{+}$, and (d) CD80 cells analyzed by flow cytometry on gated moDCs from non-PCM control subjects (CO: white bars; $n=15)$, and patients with active PCM (AP: grey bars; $n=17$ ) or treated PCM (TP: black bars; $n=22$ ), after $48 \mathrm{~h}$ of incubation with gp43 or CFA, with or without TNF- $\alpha$, or left untreated (Medium). Results expressed as means with SEM of percentages; capped lines indicate statistically significant differences with respective $p$ values: ${ }^{*} p<0.05$, ${ }^{* *} p<0.01$, or ${ }^{* * *} p<0.001$.

\subsection{Patients' MoDCs Secrete More CCL18 during Active PCM and More IL-12p40 after Antifungal Treatment}

MoDCs were analyzed by flow cytometry, and the supernatants of those cultures were assayed for IL-12p40, IL-10, IL-1 $\beta$, and CCL18 by ELISA. Levels of IL-12p40 were significantly higher on moDCs from treated PCM patients when compared with those of the controls or active disease groups, especially with TNF- $\alpha$ (Figure 3a). Supernatants were also assayed for IL-12p70, but there were no detectable levels [36]. MoDCs from both treated and active PCM groups showed levels of IL-10 and IL-1 $\beta$ similar to those 
from control cells, and there were no statistically significant differences between groups or stimuli [36]. On the other hand, chemokine CCL18 was detected at significantly higher levels in moDC cultures from the active PCM group when compared with the other groups. CFA induced moDCs from the controls to secrete more CCL18 than gp43 or unstimulated cells, and more than CFA-stimulated moDCs from the treated PCM group. In the presence of CFA, with or without TNF- $\alpha$, moDCs from active PCM patients showed similar levels to those of control subjects, and both groups had higher levels than those of the treated disease group (Figure 3b).
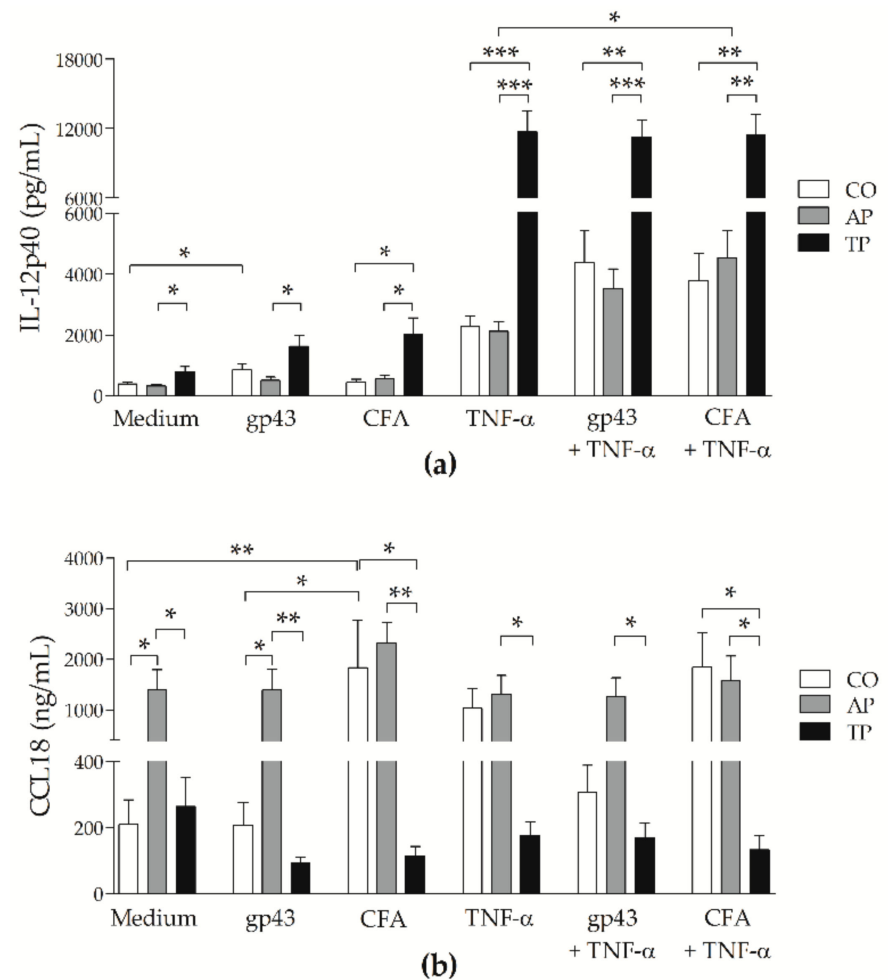

Figure 3. Influence of gp43 and CFA of P. brasiliensis on secretion of cytokines by moDCs: Enzymelinked immunosorbent assayed (ELISA) levels of (a) IL-12p40 (pg/mL), and (b) CCL18 (ng/mL) measured on moDCs of non-PCM control subjects (CO: white bars; $n=15$ ) and patients with active PCM (AP: grey bars; $n=17$ ) or treated PCM (TP: black bars; $n=22)$, after 48 h of stimulation with gp43 or CFA, with or without TNF- $\alpha$, or left untreated (Medium). Results expressed as means with SEM of levels, and capped lines indicate statistically significant differences with respective $p$ values: ${ }^{*} p<0.05,{ }^{* *} p<0.01$ or ${ }^{* * *} p<0.001$.

3.4. Cell-Free Antigen (CFA) Induces Proliferation on Peripheral Blood Mononuclear Cells (PBMCs) from Patients with Active PCM But Not Stronger than That from Treated Patients

Previously, gp43 was reported to induce in vitro antigen-specific anergy of T-cell response on PBMC cultures from PCM patients [11]. The CFA, on the other hand, has not yet been reported on human PBMC proliferation assays. Hence, we tested the ability of antigen-presenting cells in PBMCs to stimulate the proliferation of $P$. brasiliensis-specific T-lymphocytes, without the additional presence of DCs loaded with antigens. We investigated the effects of CFA at two different doses $(2$ and $5 \mu \mathrm{g} / \mathrm{mL})$ compared with gp43 at $1 \mu \mathrm{g} / \mathrm{mL}$ (determined in a previous study [35]) on cells from controls, and active and treated PCM groups (Figure 4a). PBMCs from the active PCM and control groups did not proliferate with gp 43 , but showed higher cpm values with CFA at $5 \mu \mathrm{g} / \mathrm{mL}$ compared with those of unstimulated cells (Medium; $p<0.01$ for both AP and CO). Proliferation on PBMC cultures from all groups was also positively tested with high cpm to PHA (Figure S3a). Regardless, PBMCs from the treated group showed higher proliferation with both antigens ( $p<0.05$ with gp43 and $p<0.01$ with CFA at $5 \mu \mathrm{g} / \mathrm{mL}$ versus Medium), when compared to 
that of the CO group ( $p<0.01$ with gp43 and CFA at $2 \mu \mathrm{g} / \mathrm{mL}$ and $p<0.001$ with CFA at $5 \mu \mathrm{g} / \mathrm{mL})$, and with gp43 when compared with the active PCM group $(p<0.05)$. We used an ELISA assay to determine the levels of IFN- $\gamma$ and only found higher levels in PBMCs from the treated patient group, stimulated with CFA at $5 \mu \mathrm{g} / \mathrm{mL}$, in comparison with Medium or gp43 (Figure 4b). PHA-stimulated PBMCs from PCM patients secreted high levels of IFN- $\gamma$, similarly to those from CO (Figure S3b). Supernatants were also assayed for IL-10, but detectable levels were only shown under PHA stimulus (Figure S3c).

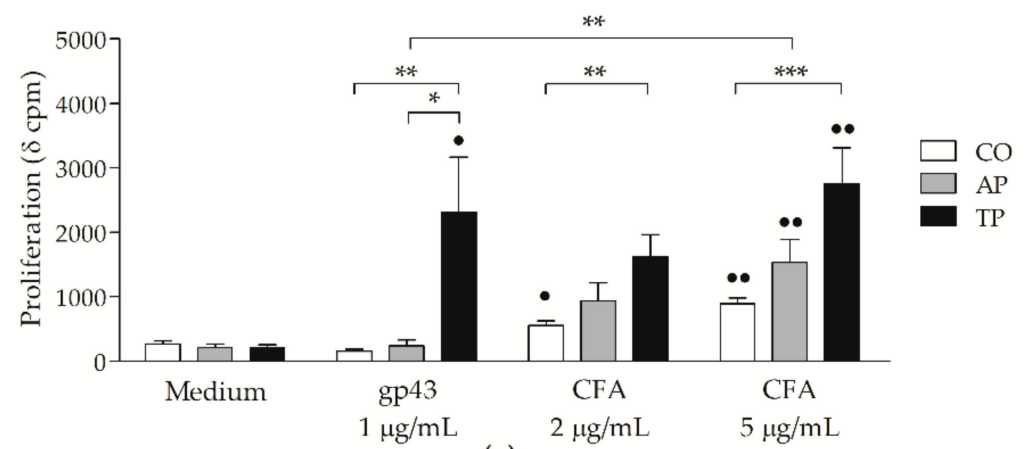

(a)

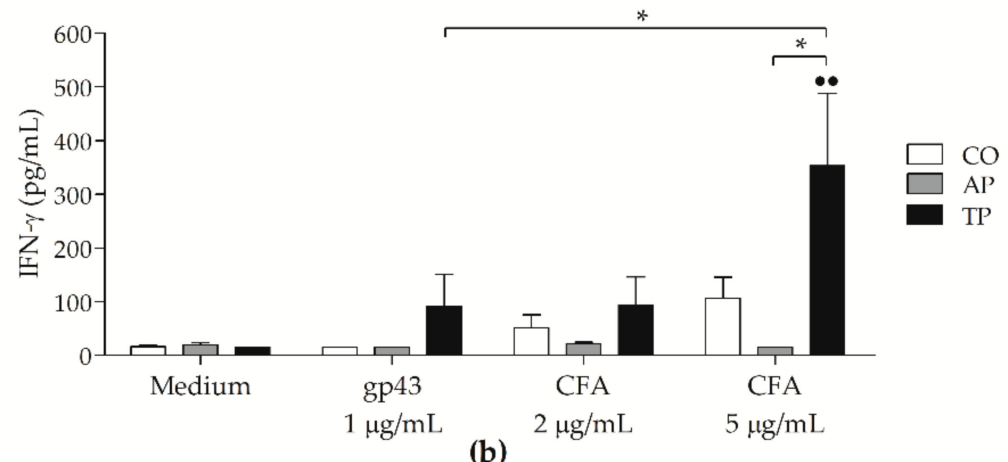

Figure 4. Induction of lymphoproliferation by P. brasiliensis antigens on peripheral blood mononuclear cells (PBMCs) culture: (a) proliferation of PBMCs was measured by $\left[{ }^{3} \mathrm{H}\right]$-thymidine uptake on cells; (b) levels of IFN- $\gamma(\mathrm{pg} / \mathrm{mL})$ determined on culture supernatants from non-PCM control subjects (CO: white bars; $n=17$ ), and patients with active PCM (AP: grey bars; $n=08$ ) or treated PCM (TP: black bars; $n=12)$, after 120 (proliferation) or $144 \mathrm{~h}(\mathrm{IFN}-\gamma)$ of stimulation with gp43 $(1 \mu \mathrm{g} / \mathrm{mL})$ or CFA ( 2 or $5 \mu \mathrm{g} / \mathrm{mL}$ ), or left untreated (Medium). Results expressed as means with SEM of $\delta \mathrm{cpm}$, and capped lines indicate statistically significant differences with respective $p$ values ${ }^{*} p<0.05,{ }^{* *} p<0.01$ or ${ }^{* * *} p<0.001$; black dots above the bars indicate differences in comparison with Medium: $\bullet p<0.05$ or $\bullet p<0.01$.

\subsection{P. brasiliensis Antigens-Stimulated MoDCs from PCM Patients Can Induce Strong Proliferative Response}

To assess whether moDCs from patients with PCM could induce antigen-specific lymphoproliferation, we cocultured previously gp43- and CFA-stimulated moDCs, with or without TNF- $\alpha$, and autologous lymphocytes. Firstly, to rule out any unspecific proliferation, we irradiated all moDC cultures with a ${ }^{60}$ Co source that inactivated any other cell type. We then thawed autologous lymphocytes and adjusted cells into 1:5 proportion (moDCs:lymphocytes) to detect the resulting proliferation after 5 days (Figure 5). The 1:10 and 1:20 ratios were also evaluated, but 1:5 showed higher proliferation levels [36]. Only basal levels of cpm were detected on cultures with irradiated moDCs or lymphocytes on medium, and significantly higher levels of cpm were verified on PHA-cultured lymphocytes, indicating there was no unspecific proliferation and confirming a high viability of thawed cells, respectively (Figure S4). 


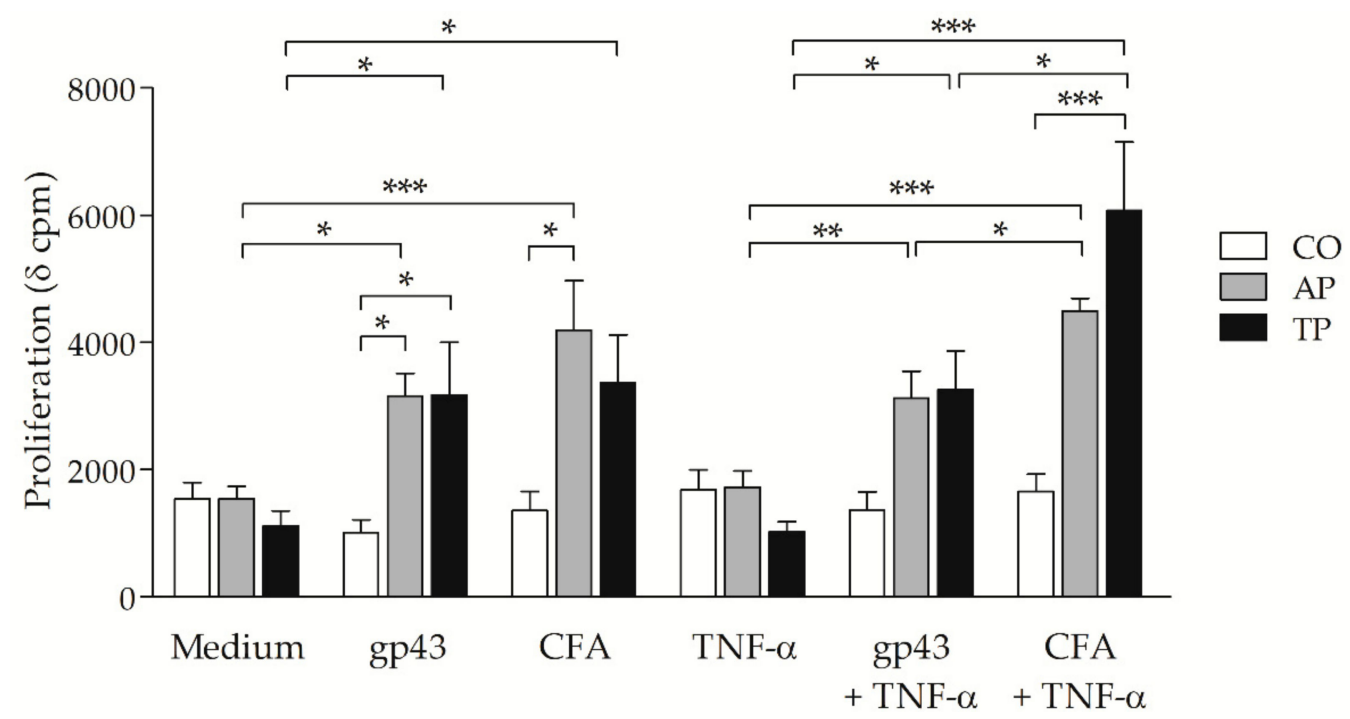

Figure 5. Influence of gp43- and CFA-stimulated moDCs on the proliferative response of autologous lymphocytes: proliferation levels measured by $\left[{ }^{3} \mathrm{H}\right]$-thymidine uptake on cocultures of autologous lymphocytes and moDCs from non-PCM control subjects (CO: white bars; $n=15)$, and patients with active PCM (AP: grey bars; $n=17$ ) or treated PCM (TP: black bars; $n=22)$ previously stimulated with gp43 or CFA, with or without TNF- $\alpha$, or left untreated (Medium), after $120 \mathrm{~h}$. Results expressed as means with SEM of $\delta \mathrm{cpm}$, and capped lines indicate statistically significant differences with respective $p$ values: ${ }^{*} p<0.05,{ }^{* *} p<0.01$, or ${ }^{* * *} p<0.001$.

With or without TNF- $\alpha$, gp43- and CFA-stimulated moDCs induced higher proliferative response on cells from active and treated PCM groups in comparison to antigen-free moDCs (Medium or TNF- $\alpha$ ). Gp43-stimulated moDCs from these groups also led to higher lymphoproliferation when compared with in the CO group. In addition, CFA + TNF- $\alpha-$ stimulated moDCs induced even higher proliferation than that by gp $43+\mathrm{TNF}-\alpha$ on both PCM groups ( $p<0.05$ on both). Importantly, cells from the CO group did not proliferate to $P$. brasiliensis antigens presented by moDCs as observed on PCM groups, confirming specific responses to gp43 and CFA.

\subsection{CFA-Stimulated MoDCs from PCM Patients Up-Regulated IFN- $\gamma$ and TNF- $\alpha$ Secretion by Lymphocytes}

In addition to the proliferative response, we investigated the levels of IFN- $\gamma$, TNF- $\alpha$, IL-4 and IL-10 in supernatants from moDCs + lymphocytes cocultures by ELISA assay. In the cultures from control, active and treated PCM groups, only basal levels of these cytokines were detected in cultures of irradiated moDCs or lymphocytes in medium, and significantly higher levels of IFN- $\gamma$, TNF- $\alpha$, and IL-10 were verified in PHA-cultured lymphocytes compared with in lymphocytes in medium (Figure S5). Increased levels of IL-4 on moDCs + Medium from all groups were likely a result of recombinant IL-4 added for the differentiation of monocytes into DCs (Figure S5c). Significantly upregulated levels of IFN- $\gamma$ and TNF- $\alpha$ were detected on cocultured lymphocytes and CFA- and CFA + TNF$\alpha$-stimulated moDCs from the active and treated PCM groups in contrast to antigen-free moDCs (Medium or TNF- $\alpha$; Figure $6 \mathrm{a}, \mathrm{b}$, respectively). However, this effect was more prominent on treated PCM. Gp43 + TNF- $\alpha$-stimulated moDCs induced the secretion of IFN- $\gamma$ on PCM patients' cells, but had little effect on TNF- $\alpha$ levels. CFA-stimulated moDCs from the treated patients led to higher levels of IL-4 compared with those of unstimulated cells or with gp43-stimulated moDCs (Figure $6 c$ ). On the active PCM group, there were higher levels of IL-10 on cocultures of gp43- and CFA + TNF- $\alpha$-stimulated moDCs and lymphocytes in comparison with those of treated patient cells. Conversely, gp43- and CFA-stimulated moDCs from the treated PCM patients, without TNF- $\alpha$, inhibited IL-10 secretion (Figure 6d). 


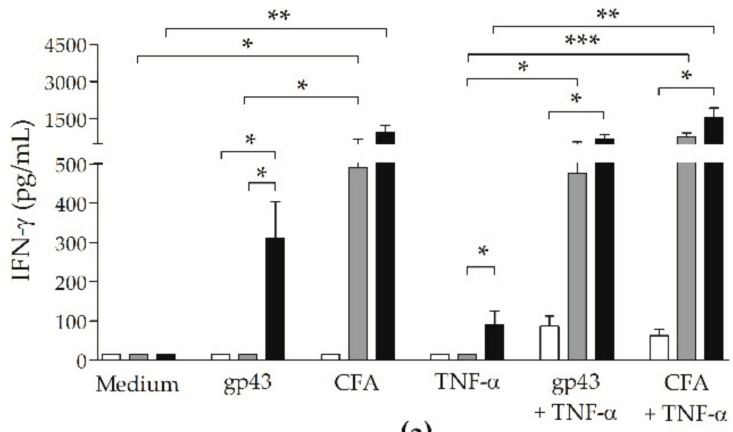

(a)

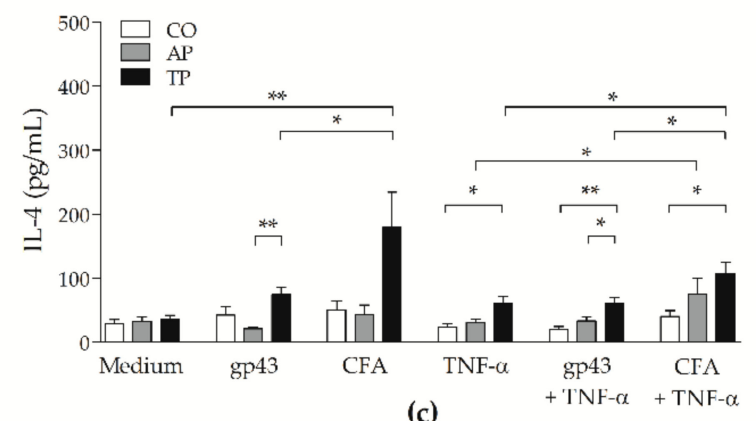

(c)

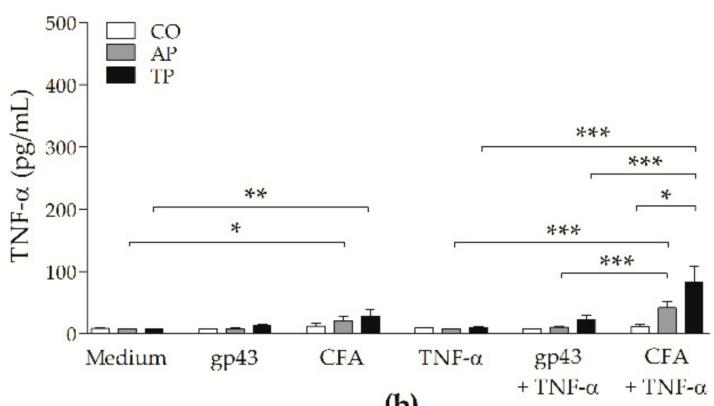

(b)

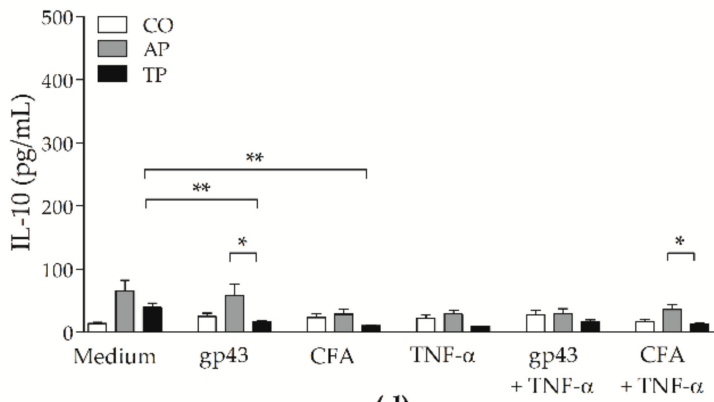

(d)

Figure 6. Influence of gp43- and CFA-stimulated moDCs on secretion of cytokines in cocultures with autologous lymphocytes. ELISA-assayed levels of (a) IFN- $\gamma$, (b) TNF- $\alpha$, (c) IL-4 and (d) IL-10 (pg/mL) were measured on cocultures of autologous lymphocytes and moDCs of non-PCM control subjects (CO: white bars; $n=15)$, and patients with active PCM (AP: grey bars; $n=17$ ) or treated PCM (TP: black bars; $n=22$ ) previously stimulated with gp43 or CFA, with or without TNF- $\alpha$, or left untreated (Medium), after $144 \mathrm{~h}$. Results expressed as means with SEM of levels, and capped lines indicate statistically significant differences with respective $p$ values: ${ }^{*} p<0.05,{ }^{* *} p<0.01$, or ${ }^{* * *} p<0.001$.

\section{Discussion}

Great advances have been achieved in the knowledge of host-parasite interactions in PCM, but several mechanisms involving the fate of infection and its progression to disease in its different clinical manifestations in humans are not known [37,38]. Additionally, studies sought new ways to modulate the cellular immune response to confer greater resistance to the host in various mycoses $[39,40]$. As the most effective APCs, DCs could be used to modulate immune responses of lymphocytes against a specific antigenic fraction. In this context, our study investigated monocyte-derived DCs from patients with PCM and their role in adaptive immune response.

Considering that the antigen presentation and the induction of a T-cell response by DCs depend on the maturation of these cells, represented by MHC-II and costimulatory molecules expression, we observed high expression of HLA-DR and CD86 on moDCs from patients with PCM, especially with TNF- $\alpha$. These results showed that moDCs from patients with active or treated PCM can be differentiated in vitro, and express surface molecules similarly or higher than that on cells from non-PCM control subjects (CO). Percentages of $\mathrm{CD}^{+} 0^{+}$cells were higher in moDCs from patients with active PCM (AP), but in general, frequencies of this molecule were low in all groups, with gp43 significantly decreasing the expression of this molecule in moDCs from patients with treated PCM (TP). Corroborating our findings, the stimulation of gp43 was associated with the low expression of MHC-II, CD86, and CD80 on DCs from P. brasiliensis-infected mice, suggesting a similar inhibitory effect of this antigen on human moDCs $[17,18]$. We did not find differences in the frequencies or MFI of DC-SIGN on moDCs from patients with PCM; nevertheless, the previously reported recognition of the polysaccharide portion of extracellular vesicles from $P$. brasiliensis by DC-SIGN encourages future studies with different antigens [41]. These vesicles constitute an unconventional transport of molecules through the fungal cell wall, but binding with DC-SIGN could have a role in facilitating phagocytosis by DCs. 
In addition, our results showed that moDCs from treated patients release considerably higher doses of IL-12p40 than cells from patients with active PCM or from the CO group do, mainly when stimulated with TNF- $\alpha$. DCs are a major source of IL-12, which is considered crucial in both human and experimental PCM, leading to a protective Th1 immune response $[9,42,43]$. Although the bioactive form is IL-12p70, the p40 subunit of IL-12 was associated with resistance to PCM [44], and found in great amounts during the late periods of $P$. brasiliensis infection [45]. We cannot ruled out the possibility of having measured both IL-12 and IL-23, which share the p 40 subunit. IL-23 is also secreted by APCs and its production is mainly activated by the binding of $\beta$-glucans on $P$. brasiliensis cell wall to dectin-1, a pattern recognition receptor expressed by DCs and other cell types [46]. This cytokine promotes the maturation of Th17 cells expressing IL-17, and Th22 cells expressing IL-22, resulting in chronic tissue inflammation. Because the great majority of patients in this study had the chronic multifocal form of PCM (86.8\%), the presence of both IL-12 and IL-23 is expected, given that these cytokines lead to a mixed immune response of Th1, Th17 and Th22, observed in this form of the disease [10]. Furthermore, our findings demonstrated that moDCs do not lose the potential of inducing an IL-12p40-associated immune response even during active PCM, with similar levels of this cytokine to those of the control group.

Although IL-1 $\beta$ induces increased secretion of IL-12 by DCs in vitro [47], in our study, this cytokine was detected at low levels in moDCs from all groups. However, considering the essential role of IL-1 $\beta$ on PCM and the recent findings on the nucleotide-binding oligomerization domain(NOD)-like receptor P3 (NLRP3) inflammasome on DCs [24], further investigation is required. Likewise, the levels of IL-10 that we observed were low and apparently downregulated by TNF- $\alpha$. Although chemokine CCL18 is induced by IL-10 on DCs [48], there were no differences in the levels of the latter that could be associated with substantial amounts of the former on active PCM patient cells in comparison with those of treated ones.

Remarkably, our study uncovered that moDCs from the active PCM group secreted larger amounts of CCL18 than those from treated patients in all evaluated conditions, and it may be a beneficial function of moDCs during active disease, as the main role of this chemokine is to attract naïve cells. This chemokine could also be induced through Pattern Recognition Receptors signaling, considering that CFA stimulated a high production of CCL18 by moDCs from non-PCM subjects. CFA is an antigen compound of various molecules, such as the $75 \mathrm{kDa}$ glycoprotein, which is immunogenic and contains a homologous amino acid sequence (87\%) to other fungi such as Aspergillus fumigatus and Coccidioides immitis [49]. CCL18 is constitutively expressed by DCs at high levels, with preferential attraction of naïve T cells, B cells, and immature moDCs, reported mainly in autoimmune disorders and other chronic inflammatory [50,51] and infectious [48,52-55] diseases. A protective role of CCL18 was shown in experimental malaria [52], and was associated with the maintenance of chronic inflammation in the lungs and liver, during tuberculosis and hepatitis C, respectively $[53,54]$. Contact with Candida albicans downregulated CCL18 on DCs and in the coculture of epithelial cells, moDCs and Aspergillus fumigatus germ tubes, the expression of this chemokine gene had a 2.377-fold change $[48,55]$. On the other hand, CCL18 was also reported as a major inducer of pulmonary cystic fibrosis and emphysema $[56,57]$. Considering that $75.5 \%$ of patients with PCM in this study had $P$. brasiliensis-related lesions in their lungs, our data suggest that this chemokine may be associated with the respiratory abnormalities frequently observed in these patients.

Recently, Amorim et al. investigated the role of NLRP3 in human PCM and found that hypoxic cells from patients, which are characterized by the intracellular expression of hypoxia-inducible transcription factor (HIF)- $1 \alpha$, had higher activation of this inflammasome than the control subjects did [37]. Typically, inflamed tissue has low levels of oxygen, triggering the HIF- $1 \alpha$ that up-regulates the IL12B gene to produce more IL-12p40, and inducing Th2 cytokines profile in DCs, which, in turn, favors the secretion of CCL18 [58,59]. Therefore, during active pulmonary chronic PCM, moDCs could have a high expression of HIF- $1 \alpha$ and NLRP3, with consequential up-regulation of IL- $1 \beta$ that favors fibrosis and 
could induce the Th22 response, with IL-21 and IL-23. In parallel, an increase in IL-18 may occur, which leads to either a Th1 response with IL-12 or Th17 response with IL-23, also associated with pulmonary fibrosis [56]. In addition, large amounts of CCL18 induce the production of collagen by pulmonary fibroblasts [50], accompanied by high levels of profibrotic growth factors, transforming growth factor beta(TGF)- $\beta$ and basic fibroblast growth factor (bFGF) [27]. With treatment, lesions ameliorate, but this does not mean full recovery of respiratory functions. The resulting sequelae, such as emphysema and fibrosis, can result in chronic hypoxia that maintains the expression of HIF-1 $\alpha$, decreasing CCL18 [59] and up-regulating IL-12p40.

Our results on PBMCs showed T-cell anergy from active PCM patients, with low IFN- $\gamma$, but undetectable IL-10 in all groups. Previous studies also reported the gp43induced antigen-specific anergy of T-cell response in PBMC cultures, with low levels of IFN- $\gamma$ but high IL-10. After treatment, PBMCs proliferate with gp43, with high levels of both cytokines $[11,60]$. The increased levels of IL-10 on those previous reports may be the result of the concentration of gp43, which was substantially higher than the $1 \mu \mathrm{g} / \mathrm{mL}$ used in the present study. Moreover, in PBMC cultures from resistant mice, CFA from the P. brasiliensis 18 strain induced high lymphoproliferation, with high IFN- $\gamma$ levels in the early phase of infection [7]. Similarly, PBMCs from patients with the active disease had increased proliferation with CFA; however, we prepared this antigen with the P. brasiliensis B-339 strain that has higher gp43 content and other immunogenic glycoproteins when compared with the 18 strain [61], which resulted in higher levels of IFN- $\gamma$ only in cells from the treated group. We confirmed gp43 in the CFA from the P. brasiliensis B-339 strain by electrophoresis [36], similar to a previous report [30]. The presence of this glycoprotein in a more complex antigenic compound may be crucial to effects observed in our study, as the immunization with a gp43-free CFA from the P. brasiliensis 18 strain, followed by infection with $P$. brasiliensis yeast induced great severity in PCM [62].

Standing as novel findings, moDCs were able to revert the in vitro antigen-specific anergy of $\mathrm{T}$ cells during the active disease, and gp43 presentation induced higher proliferation of autologous lymphocytes in comparison with control subject cells, but only up-regulated IFN- $\gamma$ with the additional stimulus of TNF- $\alpha$. CFA-stimulated moDCs had more prominent effects. They induced higher proliferation of lymphocytes from both active and treated groups in comparison with the controls, and with gp43-stimulated moDCs, also upregulating IFN- $\gamma$ and TNF- $\alpha$, corroborating results obtained in coccidioidomycosis [34]. In addition, IL-4 was higher in the treated PCM group, but with simultaneously higher levels of TNF- $\alpha$ and IFN- $\gamma$. This concomitant production of IL- 4 and IFN- $\gamma$ reported in untreated patients with the chronic multifocal form of PCM [10,63]. Hence, the present finding may reflect the tendency of treated PCM towards the Th1 response, but with IL-4 secretion, possibly explaining the long-term treatment with frequent relapses of patients with this form of the disease. It may also represent traces of untreated Th0 clones, secreting both cytokines, as described in untreated tuberculosis in comparison with Th1 clones in treated patients [64]. In spite of increased IL-4, the levels of IL-10 were downregulated by gp43 and CFA in the cocultures from the treated patients group, which was beneficial in the murine model of PCM. The absence or inactivation of IL-4 did not protect susceptible mice in P. brasiliensis infection, whereas the absence of IL-10 was associated with a favorable immune response and pathogenicity regression $[65,66]$.

The different effects of antigen presentation by moDCs became even more evident when comparing the proliferative responses to gp43 and CFA in PBMC assays and in cocultures with autologous lymphocytes. Gp43 alone induced high proliferation only in PBMCs from the treated PCM group, whereas, with moDCs, there was higher proliferation in both groups of patients compared with that in the control group. CFA, on the other hand, induced lymphoproliferation in assays with PBMCs from all groups, but only cells from the treated patients significantly proliferated more than those from the control subjects. Importantly, in the cocultures, CFA-stimulated moDCs induced significant proliferation of cells from both groups of patients, but not of the non-PCM control group. 
In our study, patients with PCM were evaluated and divided into two groups of active and cured disease, as described in Section 2. In analysis according to acute and chronic (uni- and multifocal) forms, no statistically significant differences were observed between groups, and the analysis with male patients only showed similar results to those from the analysis with both sexes [36]. Future studies with larger numbers of patients, mainly with acute and chronic unifocal forms, and patients with PCM under immunosuppression could enable further discussion on the role of DCs in severe and milder forms. In addition, a follow-up study of patients with PCM before, during, and after treatment could complement current knowledge on the variable immune responses along the evolution of this mycosis. Possible limitations in our study are the lack of evaluation of antigen effects on moDC innate mechanisms, on the modulation of other T-helper responses such as Th17 and Th22 by moDCs, and on the lymphocyte expression of costimulatory molecules or cytokine receptors.

In addition to conventional treatment with antifungal drugs, interest in alternative therapies has greatly increased in recent years, seeking the reduction of drug toxicity and improving survival in severe and fatal cases of this mycosis. In this context, significant advances were made with the use of DCs as prophylactic and therapeutic vaccines in experimental PCM [67,68].

Many questions still need answers to enable the development of more efficient and protective immune responses, such as the use of DCs in immunotherapy on human PCM. As demonstrated in our study, different antigenic fractions of P. brasiliensis can modulate DCs and induce various immune responses in cells from patients. As an additional new finding, we showed DCs' capacity to revert the characteristic in vitro immunosuppression of this disease. Hence, our study raises new prospects for the use of DCs as tools for choosing suitable fungal antigens, with subsequent analyses of immune responses and their use in immunotherapy in human PCM.

Supplementary Materials: The following are available online at https://www.mdpi.com/2309-6 08X/7/3/201/s1, Table S1: Characteristics of Active and Treated PCM Patients and Non-PCM Control Subjects, Table S2a-d: Statistical Summary, Figure S1: Gating strategy for Flow Cytometric Analyses, Figure S2: Influence of gp43 and CFA of P. brasiliensis on the Expression of Surface Molecules by MoDCs, Figure S3: Induction of Lymphoproliferation and Secretion of IFN- $\gamma$ and IL-10 by PHA on PBMC Cultures, Figure S4: Control Cultures for the Analysis of the Proliferative Response of Autologous Lymphocytes, Figure S5: Cytokines on Control Cultures of MoDCs or Autologous Lymphocytes.

Author Contributions: Conceptualization: P.K.S., T.M.O., A.S., S.R.d.A., M.A.S.-Y.; methodology: P.K.S., T.M.O., A.S.; validation: P.K.S., T.M.O.; formal analysis: P.K.S.; investigation: P.K.S., É.C.P., T.G.R.M., C.L.D.; resources: P.K.S., T.M.O., C.d.A.F.; writing-original draft preparation and visualization: P.K.S.; writing—review and editing: P.K.S., T.M.O., A.S., S.R.d.A., M.A.S.-Y.; project administration: P.K.S., M.A.S.-Y.; supervision and funding acquisition: M.A.S.-Y. All authors have read and agreed to the published version of the manuscript.

Funding: This work was supported by grants from Fundação de Amparo à Pesquisa do Estado de São Paulo (FAPESP 04/14955-3) and Fundação Faculdade de Medicina. P.K.S. (566478/2008-0) and T.G.R.M. (153263/2011-3) were supported by the Conselho Nacional de Desenvolvimento Científico e Tecnológico (CNPq); and É.C.P. was supported by the Fundação do Desenvolvimento Administrativo (FUNDAP; from Mar 2006 to Feb 2008).

Institutional Review Board Statement: The study was conducted according to the guidelines of the Declaration of Helsinki, and approved by the Research and Ethics Committee of Hospital das Clinicas HCFMUSP, Faculdade de Medicina, Universidade de Sao Paulo, Sao Paulo, SP, BR (CAPPesq 1087/04, 09 Mar 2005).

Informed Consent Statement: Informed consent was obtained from all subjects involved in the study.

Data Availability Statement: The data presented in this study are available on request from the corresponding author. The data are not publicly available due ethical restrictions. 
Acknowledgments: We thank Luciana Thomaz from the Laboratory of Mycology, Department of Microbiology, Institute of Biomedical Sciences, University of Sao Paulo, for her efforts on purifying the gp43, and Carlos P. Taborda from the Laboratory of Mycology, Department of Microbiology, Institute of Biomedical Sciences, University of Sao Paulo, for donating part of the gp43.

Conflicts of Interest: The authors declare no conflict of interest. The funders had no role in the design of the study; in the collection, analyses, or interpretation of data; in the writing of the manuscript; or in the decision to publish the results.

\section{References}

1. Coutinho, Z.F.; Wanke, B.; Travassos, C.; Oliveira, R.M.; Xavier, D.R.; Coimbra, C.E.A., Jr. Hospital morbidity due to paracoccidioidomycosis in Brazil (1998-2006). Trop. Med. Int. Health 2015, 20, 673-680. [CrossRef]

2. De Melo Teixeira, M.; Theodoro, R.C.; De Oliveira, F.F.M.; Machado, G.C.; Hahn, R.C.; Bagagli, E.; San-Blas, G.; Felipe, M.S. Paracoccidioides lutzii sp. nov.: Biological and clinical implications. Med. Mycol. 2014, 52, 19-28. [CrossRef]

3. Theodoro, R.C.; Teixeira, M.D.M.; Felipe, M.S.S.; Paduan, K.D.S.; Ribolla, P.M.; San-Blas, G.; Bagagli, E. Genus Paracoccidioides: Species Recognition and Biogeographic Aspects. PLoS ONE 2012, 7, e37694. [CrossRef] [PubMed]

4. Turissini, D.A.; Gomez, O.M.; Teixeira, M.M.; McEwen, J.G.; Matute, D.R. Species boundaries in the human pathogen Paracoccidioides. Fungal Genet. Biol. 2017, 106, 9-25. [CrossRef] [PubMed]

5. Franco, M.F.; Lacaz, L.C.; Restrepo-Moreno, A.; Del Negro, G. Paracoccidioidomycosis; CRC Press: Boca Raton, FL, USA, 1994; ISBN 0-8493-4868-4.

6. Bocca, A.L.; Amaral, A.C.; Teixeira, M.M.; Sato, P.K.; Shikanai-Yasuda, M.A.; Felipe, M.S.S. Paracoccidioidomycosis: Ecoepidemiology, taxonomy and clinical and therapeutic issues. Future Microbiol. 2013, 8, 1177-1191. [CrossRef] [PubMed]

7. Kashino, S.S.; Fazioli, R.A.; Cafalli-Favati, C.; Meloni-Bruneri, L.H.; Vaz, C.A.C.; Burger, E.; Singer, L.M.; Calich, V.L.G. Resistance to Paracoccidioides brasiliensis Infection Is Linked to a Preferential Th1 Immune Response, Whereas Susceptibility is Associated with Absence of IFN-gamma Production. J. Interf. Cytokine Res. 2000, 20, 89-97. [CrossRef] [PubMed]

8. Calich, V.L.G.; Mamoni, R.L.; Loures, F.V. Regulatory T cells in paracoccidioidomycosis. Virulence 2019, 10, 810-821. [CrossRef]

9. Oliveira, S.J.; Mamoni, R.L.; Musatti, C.C.; Papaiordanou, P.M.; Blotta, M.H.S. Cytokines and lymphocyte proliferation in juvenile and adult forms of paracoccidioidomycosis: Comparison with infected and non-infected controls. Microbes Infect. 2002, 4, 139-144. [CrossRef]

10. De Castro, L.F.; Ferreira, M.C.; Da Silva, R.M.; de Souza Lima Blotta, M.H.; Longhi, L.N.A.; Mamoni, R.L. Characterization of the immune response in human paracoccidioidomycosis. J. Infect. 2013, 67, 470-485. [CrossRef]

11. Benard, G.; Mendes-Gianinni, M.J.; Juvenale, M.; Miranda, E.T.; Duarte, A.J.S. Immunosuppression in paracoccidioidomycosis: T cell hyporesponsiveness to two Paracoccidioides brasiliensis glycoproteins that elicit strong humoral immune response. J. Infect. Dis. 1997, 175, 1263-1267. [CrossRef]

12. Karhawi, A.S.K.; Colombo, A.L.; Salomão, R. Production of IFN- $\gamma$ is impaired in patients with paracoccidioidomycosis during active disease and is restored after clinical remission. Med. Mycol. 2000, 38, 225-229. [CrossRef] [PubMed]

13. Banchereau, J.; Steinman, R.M. Dendritic cells and the control of immunity. Nature 1998, 392, 245-252. [CrossRef] [PubMed]

14. Shortman, K.; Liu, Y.-J. Mouse and human dendritic cell subtypes. Nat. Rev. Immunol. 2002, 2, 151-161. [CrossRef] [PubMed]

15. De Almeida, S.R.; Lopes, J. The low efficiency of dendritic cells and macrophages from mice susceptible to Paracoccidioides brasiliensis in inducing a Th1 response. Braz. J. Med. Biol. Res. 2001, 34, 529-537. [CrossRef] [PubMed]

16. Calich, V.L.; Singer-Vermes, L.M.; Siqueira, A.M.; Burger, E. Susceptibility and resistance of inbred mice to Paracoccidioides brasiliensis. Br. J. Exp. Pathol. 1985, 66, 585-594. [PubMed]

17. Ferreira, K.S.; Lopes, J.D.; De Almeida, S.R. Down-regulation of dendritic cell activation induced by Paracoccidioides brasiliensis. Immunol. Lett. 2004, 94, 107-114. [CrossRef]

18. Ferreira, K.; De Almeida, S.R. Immunization of susceptible mice with gp43-pulsed dendritic cells induce an increase of pulmonary Paracoccidioidomycosis. Immunol. Lett. 2006, 103, 121-126. [CrossRef]

19. Giménez, M.F.; Tausk, F.; Gigli, I. Langerhans' Cells in Paracoccidioidomycosis. Arch. Dermatol. 1987, 123, 479-481. [CrossRef]

20. Pagliari, C.; Sotto, M.N. Correlation of factor XIIIa + dermal dendrocytes with paracoccidioidomycosis skin lesions. Med. Mycol. 2002, 40, 407-410. [CrossRef]

21. Da Silva, W.L.F.; Pagliari, C.; Duarte, M.I.S.; Sotto, M.N. Paracoccidioides brasiliensis interacts with dermal dendritic cells and keratinocytes in human skin and oral mucosa lesions. Med. Mycol. 2016, 54, 370-376. [CrossRef]

22. Pagliari, C.; Kanashiro-Galo, L.; Silva, A.A.D.L.; Barboza, T.C.; Criado, P.R.; Duarte, M.I.S.; Brito, A.C.D.; Xavier, M.B.; Unger, D.; Oliveira, C.M.M.; et al. Plasmacytoid dendritic cells in cutaneous lesions of patients with chromoblastomycosis, lacaziosis, and paracoccidioidomycosis: A comparative analysis. Med. Mycol. 2014, 52, 397-402. [CrossRef]

23. Fernandes, R.K.; Bachiega, T.F.; Rodrigues, D.R.; Golim, M.D.A.; Dias-Melicio, L.A.; Balderramas, H.D.A.; Kaneno, R.; Soares, A.M.V.C. Paracoccidioides brasiliensis Interferes on Dendritic Cells Maturation by Inhibiting PGE2 Production. PLoS ONE 2015, 10, e0120948. [CrossRef]

24. De Castro, L.F.; Longhi, L.N.A.; Paião, M.R.; Justo-Júnior, A.D.S.; De Jesus, M.B.; Blotta, M.H.D.S.L.; Mamoni, R.L. NLRP3 inflammasome is involved in the recognition of Paracoccidioides brasiliensis by human dendritic cells and in the induction of Th17 cells. J. Infect. 2018, 77, 137-144. [CrossRef] [PubMed] 
25. Preite, N.W.; Feriotti, C.; De Lima, D.S.; Da Silva, B.B.; Condino-Neto, A.; Pontillo, A.; Calich, V.L.G.; Loures, F.V. The Syk-Coupled C-Type Lectin Receptors Dectin-2 and Dectin-3 Are Involved in Paracoccidioides brasiliensis Recognition by Human Plasmacytoid Dendritic Cells. Front. Immunol. 2018, 9, 464. [CrossRef] [PubMed]

26. Souza, A.C.O.; Favali, C.; Soares, N.C.; Tavares, N.M.; Jerônimo, M.S.; Junior, P.H.V.; Marina, C.L.; Santos, C.; Brodskyn, C.; Bocca, A.L. New Role of P. brasiliensis $\alpha$-Glucan: Differentiation of Non-conventional Dendritic Cells. Front. Microbiol. 2019, 10, 2445. [CrossRef] [PubMed]

27. Venturini, J.; Cavalcante, R.D.S.; Golim, M.A.; Marchetti, C.M.; Azevedo, P.Z.D.; Amorim, B.C.; De Arruda, M.S.P.; Mendes, R.P. Phenotypic and functional evaluations of peripheral blood monocytes from chronic-form paracoccidioidomycosis patients before and after treatment. BMC Infect. Dis. 2014, 14, 552. [CrossRef]

28. Sato, P.; Oshiro, T.M.; Diogo, C.L.; Passos, É.C.; Shikanai-Yasuda, M.A. Characterization of Monocyte-Derived Dendritic Cells from Patients with Active and Treated Paracoccidioidomycosis. Scand. J. Immunol. 2011, 74, 609-618. [CrossRef]

29. De Camargo, Z.; Unterkircher, C.; Campoy, S.P.; Travassos, L.R. Production of Paracoccidioides brasiliensis exoantigens for immunodiffusion tests. J. Clin. Microbiol. 1988, 26, 2147-2151. [CrossRef]

30. Camargo, Z.P.; Taborda, C.P.; Rodrigues, E.G.; Travassos, L.R. The use of cell-free antigens of Paracoccidioides brasiliensis in serological tests. J. Med. Vet. Mycol. Bimon. Publ. Int. Soc. Hum. Anim. Mycol. 1991, 29, 31-38. [CrossRef]

31. Bradford, M.M. A rapid and sensitive method for the quantitation of microgram quantities of protein utilizing the principle of protein-dye binding. Anal. Biochem. 1976, 72, 248-254. [CrossRef]

32. Laemmli, U.K. Cleavage of structural proteins during the assembly of the head of bacteriophage T4. Nature 1970, 227, 680-685. [CrossRef] [PubMed]

33. Romani, N.; Gruner, S.; Brang, D.; Kämpgen, E.; Lenz, A.; Trockenbacher, B.; Konwalinka, G.; Fritsch, P.O.; Steinman, R.M.; Schuler, G. Proliferating dendritic cell progenitors in human blood. J. Exp. Med. 1994, 180, 83-93. [CrossRef] [PubMed]

34. Richards, J.O.; Ampel, N.M.; Lake, D.F. Reversal of Coccidioidal Anergy In Vitro by Dendritic Cells from Patients with Disseminated Coccidioidomycosis. J. Immunol. 2002, 169, 2020-2025. [CrossRef] [PubMed]

35. Sadahiro, A.; Diogo, C.L.; Oshiro, T.M.; Shikanai-Yasuda, M.A. Kinetics of IFN-gamma, TNF-alpha, IL-10 and IL-4 production by mononuclear cells stimulated with gp43 peptides, in patients cured of paracoccidioidomycosis. Rev. Soc. Bras. Med. Trop. 2007, 40, 156-162. [CrossRef] [PubMed]

36. Sato, P.K. Monocyte-Derived Dendritic Cells in Human Paracoccidioidomycosis. Unpublished work. 2021.

37. Amorim, B.C.; Pereira-Latini, A.C.; Golim, M.D.A.; Júnior, R.L.R.; Yoo, H.H.B.; De Arruda, M.S.P.; Tavares, A.H.; Cavalcante, R.D.S.; Mendes, R.P.; Pontillo, A.; et al. Enhanced expression of NLRP3 inflammasome components by monocytes of patients with pulmonary paracoccidioidomycosis is associated with smoking and intracellular hypoxemia. Microbes Infect. 2020, 22, 137-143. [CrossRef]

38. De Araújo, E.F.; Preite, N.W.; Veldhoen, M.; Loures, F.V.; Calich, V.L.G. Pulmonary paracoccidioidomycosis in AhR deficient hosts is severe and associated with defective Treg and Th22 responses. Sci. Rep. 2020, 10, 1-16. [CrossRef]

39. Czakai, K.; Dittrich, M.; Kaltdorf, M.; Müller, T.; Krappmann, S.; Schedler, A.; Bonin, M.; Edühring, S.; Schuster, S.; Speth, C.; et al. Influence of Platelet-rich Plasma on the immune response of human monocyte-derived dendritic cells and macrophages stimulated with Aspergillus fumigatus. Int. J. Med. Microbiol. 2017, 307, 95-107. [CrossRef]

40. Coady, A.; Sil, A. MyD88-Dependent Signaling Drives Host Survival and Early Cytokine Production during Histoplasma capsulatum Infection. Infect. Immun. 2015, 83, 1265-1275. [CrossRef]

41. Da Silva, R.P.; Heiss, C.; Black, I.; Azadi, P.; Gerlach, J.Q.; Travassos, L.R.; Joshi, L.; Kilcoyne, M.; Puccia, R. Extracellular vesicles from Paracoccidioides pathogenic species transport polysaccharide and expose ligands for DC-SIGN receptors. Sci. Rep. 2015, 5, srep14213. [CrossRef]

42. Romano, C.C.; Mendesgiannini, M.J.S.; Duarte, A.J.; Benard, G. The role of interleukin-10 in the differential expression of interleukin-12p70 and its $\beta 2$ receptor on patients with active or treated paracoccidioidomycosis and healthy infected subjects. Clin. Immunol. 2005, 114, 86-94. [CrossRef] [PubMed]

43. Arruda, C.; Franco, M.F.; Kashino, S.S.; Nascimento, F.R.F.D.; Fazioli, R.D.A.; Vaz, C.A.; Russo, M.; Calich, V.L.G. Interleukin-12 Protects Mice against Disseminated Infection Caused by Paracoccidioides brasiliensis but Enhances Pulmonary Inflammation. Clin. Immunol. 2002, 103, 185-195. [CrossRef] [PubMed]

44. Livonesi, M.C.; Souto, J.T.; Campanelli, A.P.; Maffei, C.M.L.; Martinez, R.; Rossi, M.A.; Da Silva, J.S. Deficiency of IL-12p40 subunit determines severe paracoccidioidomycosis in mice. Med. Mycol. 2008, 46, 637-646. [CrossRef] [PubMed]

45. Lopera, D.; Naranjo, T.W.; Cruz, O.G.; Restrepo, Á.; Cano, L.E.; Lenzi, H.L. Structural and Topographic Dynamics of Pulmonary Histopathology and Local Cytokine Profiles in Paracoccidioides brasiliensis Conidia-Infected Mice. PLoS Neglected Trop. Dis. 2011, 5, e1232. [CrossRef]

46. Tristão, F.S.M.; Rocha, F.A.; Carlos, D.; Ketelut-Carneiro, N.; Souza, C.O.S.; Milanezi, C.M.; Silva, J.S. Th17-Inducing Cytokines IL-6 and IL-23 Are Crucial for Granuloma Formation during Experimental Paracoccidioidomycosis. Front. Immunol. 2017, 8, 949. [CrossRef] [PubMed]

47. Nakahara, T.; Urabe, K.; Fukagawa, S.; Uchi, H.; Inaba, K.; Furue, M.; Moroi, Y. Engagement of human monocyte-derived dendritic cells into interleukin (IL)-12 producers by IL-1b + interferon (IFN)-g. Clin. Exp. Immunol. 2005, 139, 476-482. [CrossRef]

48. Vulcano, M.; Struyf, S.; Scapini, P.; Cassatella, M.; Bernasconi, S.; Bonecchi, R.; Calleri, A.; Penna, G.; Adorini, L.; Luini, W.; et al. Unique Regulation of CCL18 Production by Maturing Dendritic Cells. J. Immunol. 2003, 170, 3843-3849. [CrossRef] 
49. Xander, P.; Vigna, A.F.; Feitosa, L.D.S.; Pugliese, L.; Bailão, A.M.; Soares, C.M.D.A.; Mortara, R.A.; Mariano, M.; Lopes, J.D. A surface 75-kDa protein with acid phosphatase activity recognized by monoclonal antibodies that inhibit Paracoccidioides brasiliensis growth. Microbes Infect. 2007, 9, 1484-1492. [CrossRef]

50. Schutyser, E.; Richmond, A.; Van Damme, J. Involvement of CC chemokine ligand 18 (CCL18) in normal and pathological processes. J. Leukoc. Biol. 2005, 78, 14-26. [CrossRef]

51. Rademacher, J.; Kill, A.; Mattat, K.; Dragun, D.; Siegert, E.; Günther, J.; Riemekasten, G. Monocytic Angiotensin and Endothelin Receptor Imbalance Modulate Secretion of the Profibrotic Chemokine Ligand 18. J. Rheumatol. 2016, 43, 587-591. [CrossRef]

52. Bruna-Romero, O.; Schmieg, J.; Del Val, M.; Buschle, M.; Tsuji, M. The Dendritic Cell-Specific Chemokine, Dendritic Cell-Derived CC Chemokine 1, Enhances Protective Cell-Mediated Immunity to Murine Malaria. J. Immunol. 2003, 170, 3195-3203. [CrossRef] [PubMed]

53. Mendez, A.; Hernández-Pando, R.; Contreras, S.; Aguilar, D.; Rook, G. CCL2, CCL18 and sIL-4R in renal, meningeal and pulmonary TB; a 2 year study of patients and contacts. Tuberculosis 2011, 91, 140-145. [CrossRef] [PubMed]

54. Kusano, F.; Tanaka, Y.; Marumo, F.; Sato, C. Expression of C-C chemokines is associated with portal and periportal inflammation in the liver of patients with chronic hepatitis C. Lab. Investig. 2000, 80, 415-422. [CrossRef] [PubMed]

55. Morton, C.O.; Fliesser, M.; Dittrich, M.; Mueller, T.; Bauer, R.; Kneitz, S.; Hope, W.; Rogers, T.R.; Einsele, H.; Loeffler, J. Gene Expression Profiles of Human Dendritic Cells Interacting with Aspergillus fumigatus in a Bilayer Model of the Alveolar Epithelium/Endothelium Interface. PLoS ONE 2014, 9, e98279. [CrossRef] [PubMed]

56. Hector, A.; Kröner, C.; Carevic, M.; Bakele, M.; Rieber, N.; Riethmüller, J.; Griese, M.; Zissel, G.; Hartl, D. The chemokine CCL18 characterises Pseudomonas infections in cystic fibrosis lung disease. Eur. Respir. J. 2014, 44, 1608-1615. [CrossRef]

57. Rong, B.; Fu, T.; Rong, C.; Liu, W.; Li, K.; Liu, H. Association between serum CCL-18 and IL-23 concentrations and disease progression of chronic obstructive pulmonary disease. Sci. Rep. 2020, 10, 1-9. [CrossRef]

58. Korbecki, J.; Olbromski, M.; Dziegiel, P. CCL18 in the Progression of Cancer. Int. J. Mol. Sci. 2020, 21, 7955. [CrossRef]

59. Bosco, M.C.; Puppo, M.; Santangelo, C.; Anfosso, L.; Pfeffer, U.; Fardin, P.; Battaglia, F.; Varesio, L. Hypoxia Modifies the Transcriptome of Primary Human Monocytes: Modulation of Novel Immune-Related Genes and Identification Of CC-Chemokine Ligand 20 as a New Hypoxia-Inducible Gene. J. Immunol. 2006, 177, 1941-1955. [CrossRef]

60. Benard, G.; Romano, C.C.; Cacere, C.R.; Juvenale, M.; Mendes-Giannini, M.J.S.; Duarte, A.J. Imbalance of IL-2, IFN- $\gamma$ and IL-10 Secretion in the Immunosuppression Associated with Human Paracoccidioidomycosis. Cytokine 2001, 13, 248-252. [CrossRef]

61. Panunto-Castelo, A.; Freitas-Da-Silva, G.; Bragheto, I.C.; Martinez, R.; Roque-Barreira, M.C. Paracoccidioides brasiliensis exoantigens: Recognition by IgG from patients with different clinical forms of paracoccidioidomycosis. Microbes Infect. 2003, 5, $1205-1211$. [CrossRef]

62. Cavassani, K.A.; Tristao, F.S.M.; De Oliveira, L.L.; Rocha, F.A.; Vancim, J.O.; Moreira, A.P.; Campanelli, A.P.; Panagio, L.A.; Milanezi, C.M.; Martinez, R.; et al. Cell-Free Antigens from Paracoccidioides brasiliensis Drive IL-4 Production and Increase the Severity of Paracoccidioidomycosis. PLoS ONE 2011, 6, e21423. [CrossRef] [PubMed]

63. De Mello, L.M.; Silva-Vergara, M.L.; Junior, V.R.; Junior, V.R. Patients with active infection with Paracoccidioides brasiliensis present a Th2 immune response characterized by high Interleukin-4 and Interleukin-5 production. Hum. Immunol. 2002, 63, 149-154. [CrossRef]

64. Marchant, A.; Amedei, A.; Azzurri, A.; Vekemans, J.; Benagiano, M.; Tamburini, C.; Lienhardt, C.; Corrah, T.; McAdam, K.P.W.J.; Romagnani, S.; et al. Polarization of PPD-Specific T-Cell Response of Patients with Tuberculosis from Th0 to Th1 Profile after Successful Antimycobacterial Therapy or In Vitro Conditioning with Interferon- $\alpha$ or Interleukin-12. Am. J. Respir. Cell Mol. Biol. 2001, 24, 187-194. [CrossRef] [PubMed]

65. Arruda, C.; Valente, R.; Pina, A.; Kashino, S.S.; Fazioli, R.A.; Vaz, C.A.C.; Franco, M.F.; Keller, A.C.; Calich, V.L.G. Dual Role of Interleukin-4 (IL-4) in Pulmonary Paracoccidioidomycosis: Endogenous IL-4 Can Induce Protection or Exacerbation of Disease Depending on the Host Genetic Pattern. Infect. Immun. 2004, 72, 3932-3940. [CrossRef] [PubMed]

66. Da Costa, T.A.; Bazan, S.B.; Feriotti, C.; De Araujo, E.F.; Bassi, Ê.J.; Loures, F.V.; Calich, V.L.G. In Pulmonary Paracoccidioidomycosis IL-10 Deficiency Leads to Increased Immunity and Regressive Infection without Enhancing Tissue Pathology. PLoS Neglected Trop. Dis. 2013, 7, e2512. [CrossRef] [PubMed]

67. Jannuzzi, G.P.; Tavares, A.H.F.P.; Kaihami, G.H.; De Almeida, J.R.F.; De Almeida, S.R.; Ferreira, K.S. scFv from Antibody That Mimics gp43 Modulates the Cellular and Humoral Immune Responses during Experimental Paracoccidioidomycosis. PLoS ONE 2015, 10, e0129401. [CrossRef] [PubMed]

68. Silva, L.B.R.; Taira, C.L.; Dias, L.S.; Souza, A.C.O.; Nosanchuk, J.D.; Travassos, L.R.; Taborda, C.P. Experimental Therapy of Paracoccidioidomycosis Using P10-Primed Monocyte-Derived Dendritic Cells Isolated from Infected Mice. Front. Microbiol. 2019, 10, 1727. [CrossRef] 